Haya: The Saudi Journal of Life Sciences

Abbreviated Key Title: Haya Saudi J Life Sci ISSN 2415-623X (Print) |ISSN 2415-6221 (Online) Scholars Middle East Publishers, Dubai, United Arab Emirates Journal homepage: https://saudijournals.com/sjls

Original Research Article

\title{
DNA Barcoding of Withania somnifera (L) Dunal Using Trnh-Psba Gene Sequences
}

\author{
Fathaunnisha $\mathrm{S}^{1}$, Hemamalini $\mathrm{V}^{2 *}$, Jayasudha $\mathrm{H}^{3}$, Sridhar $\mathrm{R}^{4}$ \\ ${ }^{1,3}$ Research Scholar, Department of Plant Biology and Plant Biotechnology, Quaid-E-Millath Government College For Women, Chennai-600002, Tamil \\ Nadu, India \\ ${ }^{2}$ Assistant Professor, Department of Plant Biology and Plant Biotechnology, Quaid-E-Millath Government College For Women, Chennai-600002, \\ Tamil Nadu, India \\ ${ }^{4}$ Research Scholar, Department of Education, Tamil Nadu Open University, Chennai-600015, Tamil Nadu, India
}

DOI: $10.36348 /$ sjls.2020.v05i10.002 $\quad$ | Received: 26.09.2020 | Accepted: 06.10.2020 | Published: 10.10 .2020

*Corresponding author: V. Hemamalini

\section{Abstract}

Objective: In this present study, the DNA barcoding method has been applied to define and authenticate collected plant material as W. somnifera from its closely linked species at the molecular level and the organization of $\operatorname{trn} H-p s b A$ in $W$. somnifera and its potential as a DNA barcode. Method: The plant samples were collected from Pannapatti, Salem district. The tissue from the leaf was extracted. Isolation of the genomic DNA was carried out using CTAB technique. Polymerase chain reaction (PCR) was carried out and amplified a specific region of the chloroplast using trnH-psbA and analyzed PCR products by gel electrophoresis. The Basic Local Alignment Search Tool (BLAST) was used to identify sequences in databases. The sequence information was used to construct a phylogenetic tree by Maximum Likelihood Method using MEGA X. This tree-building tool is used to analyze the phylogenetic relationship of W. somnifera. Results: DNA yield was good with $50 \mathrm{ng}$. The purity of the DNA was also calculated and it was 1.7. Phylogenetic tree constructed showed maximum resolved topology for internal branches of $82 \%$ bootstrap value with species-specific clusters with W. somnifera. Conclusion: W. somnifera are an indigenous plant of India and an important plant in the Indian Traditional Medicinal System. To improve and enhance the utilization of this plant species for further study as medicine, accurate, proper identification and authentication is very important.

Keywords: Cetyltrimethylammonium bromide (CTAB); DNA Barcoding; Chloroplast; molecular phylogeny; trnH-psbA.

Copyright (C) 2020 The Author(s): This is an open-access article distributed under the terms of the Creative Commons Attribution 4.0 International License (CC BY-NC 4.0) which permits unrestricted use, distribution, and reproduction in any medium for non-commercial use provided the original author and source are credited.

\section{INTRODUCTION}

The world has an estimated 300,000 plant species (IUCN, 2012), but relatively few of them can be identified based on traditional methods of plant identification [1]. Even for expert taxonomists, correct classification and description of this large number is a significant challenge. DNA barcoding has had a positive impact on the classification and recognition of species [2]. DNA barcoding is an innovative method aimed to provide a quick, accurate, and automated identification of species through the use of short and standardized gene regions [3]. The theory of DNA barcoding is derived from the small, uniform sequence of DNA can also be used to classify and differentiate between species in the tree of life. DNA barcoding does not guarantee full taxonomic resolution by using a single gene region, but it does promise proximity [4]. DNA barcoding is a powerful tool to help classify organisms with broad applications in conventional taxonomy, ecology, food analytics, forensics, and environmental science [5]. For animals, a 648-bp long Folmer region of the Cytochrome C Oxidase 1 (CO1) mitochondrial gene is the barcode used with effectiveness. Nevertheless, no such universal barcode has yet been found in plants $[6,7]$. Low substitution rates of mitochondrial DNA have led to the search for alternative barcoding regions. From initial investigations of plastid regions 7 leading candidates have emerged [8].

Numerous diverse plant barcode sequences were suggested by different researchers based on a single chloroplast namely $\mathrm{rpoC} 1$, rpoB , rbcL, matK, trnH-psbA, atpF and some combinations sequences were also acclaimed which include $\mathrm{rpoC} 1+$ matK + trnH-psbA or rpoC1 1 rpoB + matK, rbcL $+t r n H-p s b A$ , matK + atpF/H + trnH-psbA and matK + atpF/H + psbK/I [9]. Four plant DNA barcode markers, rbcL, matK, trnH- psbA, and ITS2, have been developed in 
the last decades [10]. The Consortium for the Barcode of Life (CBOL) Plant Working Group suggested, the chloroplast gene $\mathrm{rbcL}$ and matK as the core barcodes for plant species, as well as the intergenic sequence trnH-psbA and the nuclear gene ITS as supplemented barcodes [11]. In green plants, the chloroplast genome is much simpler in structural complexity than the nuclear genome and typically has a highly conserved structure and gene content across organisms [12]. DNA barcoding can provide an alternative means of estimating species diversity in field identification skills and in a much shorter time frame without high-level expertise. It is an effective, simple, low-cost, and standard method for assessing and identifying various plant species [13].

The three vital principles of DNA barcoding are minimalism, standardization, and scalability [14]. Most important studies have shown that chloroplast genomes are characterized by different clusters of mutations known as "hotspots" or wildly varying regions that may serve as DNA markers for the accurate identification of plant species [15-16]. DNA barcoding, next-generation sequencing, and microarray technology have developed as potential techniques and promising tools to elucidate and conserve plant genetic diversity. They are extremely helpful in authenticating valuable medicinal plants for the preparation of herbal drugs [17]. The internal transcribed spacer region and the plastid trnH-psbA intergenic spacer are potentially usable DNA regions for applying barcoding to flowering plants. [18]. Compared to the difficulty and subjective biases associated with morphology-based taxa identification, DNA barcoding is currently becoming popular due to its simplicity and high accuracy [19].

Withania somnifera (L.) Dunal, a power herb of the family Solanaceae, has multiple medicinal properties. W. somnifera is one of India's 36 highly commercialized medicinal plants [20]. W. somnifera, an indigenous plant of India widely used various indigenous medicinal systems such as Siddha, Ayurveda, Unani, and Allopathy [21]. W. somnifera roots are compared with Ginseng roots because of its restorative properties and have been given the name Indian Ginseng [22]. An extensive range of biological activities have been reported from $W$. somnifera rhizome, root and leaves namely, antimicrobial [23], antifungal and antioxidant [24], antiobesity [25], anticancer [26], anti-inflammatory [27], antiarthritic [28], neuroprotective [29], antiepileptic [30-32], antidepressant, [33] and anti-anxiety [34]. Its other restorative properties include hepatoprotective [34], hypoglycaemic and hypolipidemic [35-37], sexual vitality as an adaptogen [38]. W. somnifera seeds also possess unique medicinal benefits includes antihelminthic, eliminate white corneal spots, increase the count of sperm, and increase the development of the testicles [39].
In this context, the W.somnifera plant has been used in the world for decades to preserve health and cure more chronic diseases. However, the adulteration and use of counterfeit products as replacements have become a major concern for consumers and industry on safety and efficacy grounds. Thus, medicinal plant authentication is of the highest concern [40, 41]. Therefore, the accurate identification and collection of this medicinal herb are vital to enhancing the drug's efficacy and biosafety. The objective of the present study is to evaluate an ideal barcode candidate for distinguishing and authenticating the species of $W$. somnifera using the trnH-psbA intergenic spacer region.

\section{METHODOLOGY}

DNA Isolation, Amplification, and Sequencing of the trnH-psbA gene: The DNA from the sample was extracted by using modified CTAB according to AboulMaaty et al. using $100 \mathrm{mg}$ of fresh leaves. The quality of isolated genomic DNA was checked electrophoretically on $0.8 \%$ TAE (Tris-acetate-EDTA) Agarose gel. The trnH-psbA intergenic region was amplified using the primers listed in Table 1. The polymerase chain reaction was performed in $20 \mu \mathrm{l}$ reaction mixture contained $1-\mathrm{X}$ buffer, $1 \mathrm{U}$ Taq DNA polymerase, $0.2 \mathrm{mM}$ of dNTPs, $0.5 \mu \mathrm{M}$ each of the forward and reverse primers, and $50 \mathrm{ng}$ of genomic DNA were added. The PCR programmed for initial denaturation at $94^{\circ} \mathrm{C}$ for 5 minutes, denaturation at $94^{\circ} \mathrm{C}$ for 45 seconds, Primer annealing at $55^{\circ} \mathrm{C}$ for 45 seconds, Extension at $72^{\circ} \mathrm{C}$ for 1 minute 20 seconds for 35 cycles, Final extension@ $972^{\circ} \mathrm{C}$ for 7 minutes. The PCR products were run on $1 \% \mathrm{TAE}$ Agarose gels containing Ethidium bromide (EtBr) and visualized on a UV trans-illuminator. The sequencing was done by applied biosytems 3500 genetic analyzer using Sanger sequencing.

\begin{tabular}{|c|c|}
\hline \multicolumn{2}{|c|}{ Table-1: Primer Details } \\
\hline trnH-psbA F & ACTGCCTTGATCCACTTGGC \\
\hline trnH-psbA R & CGAAGCTCCATCTACAAATGG \\
\hline
\end{tabular}

\section{Data Analysis and Species Identification}

The chromatograms obtained after sequencing were base called and forward and reverse sequences were trimmed-and assembled. Similarity search is an important methodology in DNA barcoding. Nucleotide blast (BLASTn) using BLAST program and Genbank nucleotide database with default parameters was performed to determine the identity and the closest known relatives of the sequences obtained. The sequences were aligned using the MUSCLE algorithm in MEGA $X$. The interspecific and intraspecific divergences were calculated using MEGAX software. A phylogenetic tree was constructed using Maximum Likelihood Method. Insertion and deletion were treated as missing data. All characters were equally weighted and unordered. The evaluation of the internal support of clades was conducted by bootstrap analysis using 1,000 replicates. 


\section{RESULTS}

Genomic DNA Extraction and PCR Amplification: Isolated genomic DNA and PCR amplicons for trnH-psbA were resolved using the Agarose gel. Barcode regions must be relatively short in length to facilitate easy PCR amplification and DNA sequencing. The trnH-psbA was amplified using a single pair of universal primers that resulted in efficient amplification and sequencing. This sequence was used as a query sequence in BLAST at NCBI to find a similar sequence. The trnH-psbA sequences of $W$. somnifera had $96 \%$ similarity with other sequences of W. somnifera, available on BLAST at NCBI (Fig. 1).

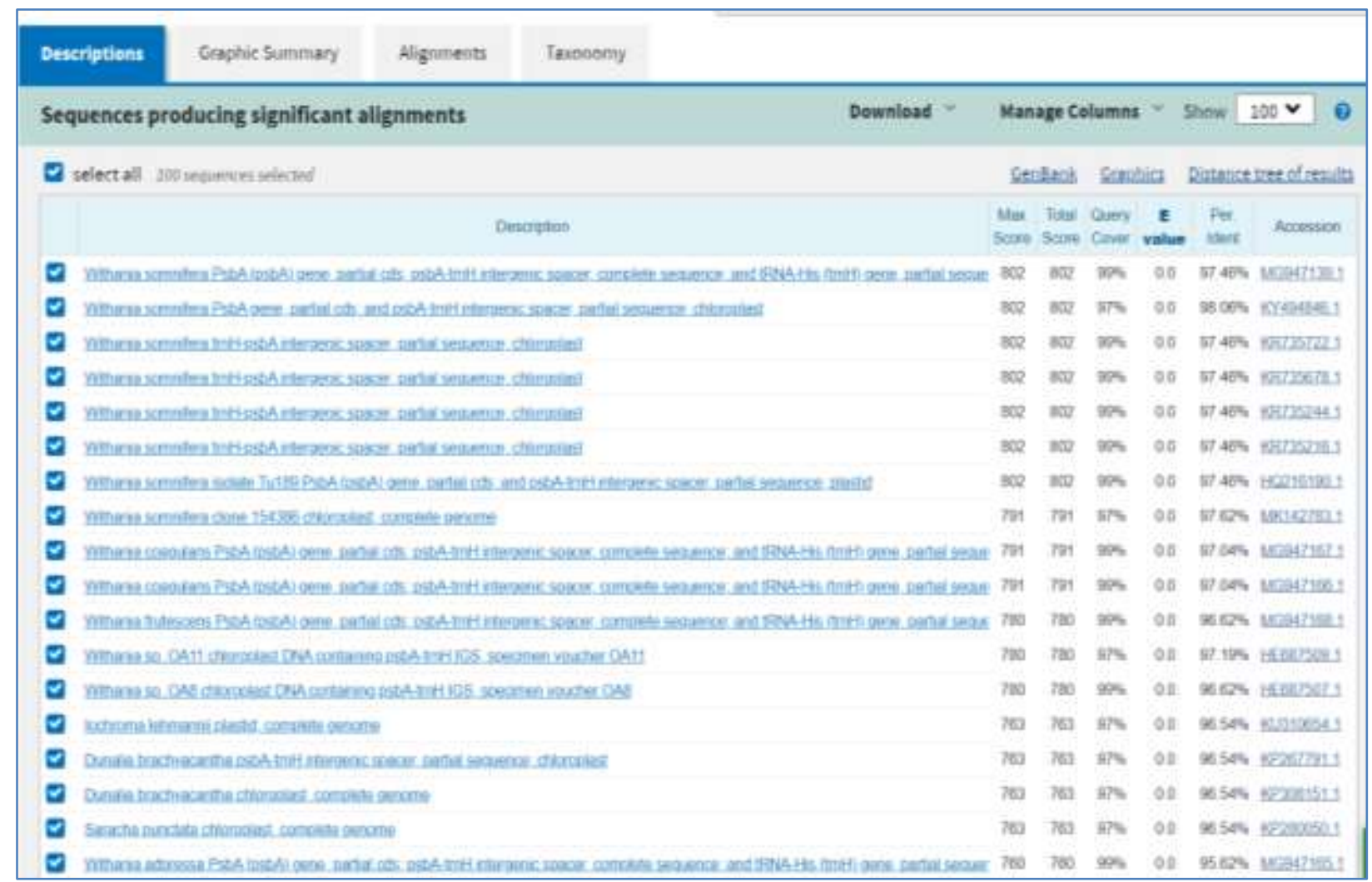

Fig-1: BLAST result of $W$. somnifera

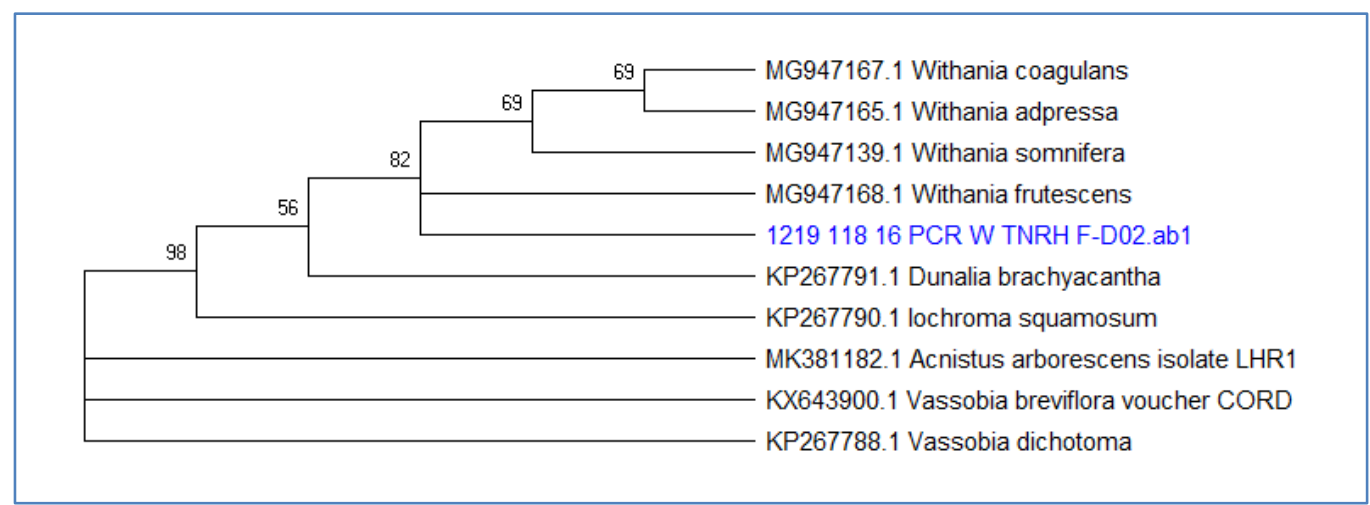

Fig-2: Maximum Likelihood Phylogenetic Tree of W. somnifera using trnH-psbA gene Sequence

\section{PHYLOGENETIC TREE}

The phylogenetic tree constructed showed maximum resolved topology for internal branches of $82 \%$ bootstrap value with species-specific clusters with W. somnifera.

\section{DISCUSSION}

DNA barcoding has been proven to help identify recently diverged species in some cases, whereas in other, barcodes of the species under study were not distinctive. Since 1957, several studies conducted on $W$. somnifera have highlighted intraspecific variations and differences between the wild and cultivated plants of this species. The commercial value of $W$. somnifera has received more attention due to its unique medicinal properties. Its accurate identification is therefore of great importance. Yet it is extremely difficult to identify this plant-based on morphological characteristics. Recent molecular approaches, such as 
DNA barcoding have been commonly used for species identification, diversity, forensic medicine, and ecological science. It also plays a significant role in distinguishing common medicinal herbs [43]. The success of an individual locus as the barcode depends not only on its ability to discriminate against species but also on its success in amplification and sequencing. . In the present work, we used the chloroplast trnH-psbA region for barcoding $W$. somnifera plant.

A similar pattern has been showing for other land plant groups, with trnH-psbA PCR amplification and sequencing rates high enough to be considered as barcode loci [44]. The chloroplast trnH-psbA demonstrated good amplification across land plants with a single pair of primers and high levels of species discrimination. The trnH-psbA is an intergenic spacer with high discriminatory power with high universality.

The second method used in the present study was based on phylogenetic trees, which are constructed based on distances obtained in the sequences of the candidate loci. It provides a graphical representation that is easy to analyze. The species discriminatory power of locus is determined based on the visualized percent monopoly. Based on this method, the loci $t r n H$ psbA discriminated the accessions of the species clustered on the same clade. BLAST results unequivocally demonstrated the discriminatory power of the tested loci for species. These results also confirmed that the sequences generated in the present study were of only the targeted loci. As of trnH-psbA sequences of $W$. somnifera matched $100 \%$ with the sequence of $W$. somnifera. The character-based analysis of sequence revealed species-specific characters, i.e. distinctive bases at the corresponding positions of the accession of the species compared.

\section{CONCLUSION}

The basic purpose of this study was to improve and simplify the DNA extraction protocol and to authenticate plant material collected from the Salem district for further studies as food and medicine. This study develops DNA barcodes for W. somnifera species of the Solanaceae family. The results of this study do not only support species identification and analysis of genetic relationships among some species of the Solanaceae family but also contributed to the conservation and commercialization of this economically important medicinal plant.

\section{REFERENCES}

1. Li, X., Yang, Y., Henry, R.J., Rossetto, M., Wang, Y. and Chen, S. (2015). Plant DNA barcoding: from gene to genome. Biol Rev, 90: 157-166.

2. Paul D. N. Hebert, T. Ryan Gregory. (2005). The Promise of DNA Barcoding for Taxonomy, Systematic Biology, 54(5), Pages 852859.
3. Manzanilla, V., Kool, A., Nhat, L. N., Van, H. N., Thu, H. L. T., \& De Boer, H. J. (2018). Phylogenomics and barcoding of Panax: toward the identification of ginseng species. BMC evolutionary biology, 18(1), 1-14.

4. Hebert, P. D., Cywinska, A., Ball, S. L., \& Dewaard, J. R. (2003). Biological identifications through DNA barcodes. Proceedings of the Royal Society of London. Series B: Biological Sciences, 270(1512), 313-321.

5. Gostel, M. R., Zúñiga, J. D., Kress, W. J., Funk, V. A., \& Puente-Lelievre, C. (2020). Microfluidic Enrichment Barcoding (MEBarcoding): a new method for high throughput plant DNA barcoding. Scientific Reports, 10(1), 1-13.

6. Valentini, A., Pompanon, F., \& Taberlet, P. (2009). DNA barcoding for ecologists. Trends in ecology \& evolution, 24(2), 110-117.

7. Parveen, I., Singh, H. K., Raghuvanshi, S., Pradhan, U. C., \& Babbar, S. B. (2012). DNA barcoding of endangered Indian Paphiopedilum species. Molecular Ecology Resources, 12(1), 8290.

8. Chase, M. W., Cowan, R. S., Hollingsworth, P. M., van den Berg, C., Madriñán, S., Petersen, G., ... \& Pedersen, N. (2007). A proposal for a standardised protocol to barcode all land plants. Taxon, 56(2), 295-299.

9. Shinwari, Z. K., Jan, S. A., Khalil, A. T., Khan, A., Ali, M., Qaiser, M., \& Zahra, N. B. (2018). Identification and phylogenetic analysis of selected medicinal plant species from pakistan: dna barcoding approach. Pak. J. Bot, 50(2), 553-560.

10. Kress, W. J. (2017). Plant DNA barcodes: Applications today and in the future. Journal of systematics and evolution, 55(4), 291-307.

11. Group, C. P. W., Hollingsworth, P. M., Forrest, L. L., Spouge, J. L., Hajibabaei, M., Ratnasingham, S., ... \& Fazekas, A. J. (2009). A DNA barcode for land plants. Proceedings of the National Academy of Sciences, 106(31), 12794-12797.

12. Kang, Y., Deng, Z., Zang, R., \& Long, W. (2017). DNA barcoding analysis and phylogenetic relationships of tree species in tropical cloud forests. Scientific reports, 7(1), 1-9.

13. Shaheen, S., Ramzan, S., Haroon, N., Jalal, M., Javad, S., Sarwar, S., \& Khalid, S. (2015). Traditional plants of family solanaceae facing the problem of adulteration: a critical issue. Pakistan Journal of Science, 67(4), 329.

14. Hollingsworth, P. M., Graham, S. W., \& Little, D. P. (2011). Choosing and using a plant DNA barcode. PloS one, 6(5), e19254.

15. Dong, W., Liu, J., Yu, J., Wang, L., \& Zhou, S. (2012). Highly variable chloroplast markers for evaluating plant phylogeny at low taxonomic levels and for DNA barcoding. PloS one, 7(4), e35071.

16. Song, Y., Zhang, Y., Xu, J., Li, W., \& Li, M. (2019). Characterization of the complete chloroplast genome sequence of Dalbergia species 
and its phylogenetic implications. Scientific reports, 9(1), 1-10.

17. Sarwat, M., \& Yamdagni, M. M. (2016). DNA barcoding, microarrays and next generation sequencing: recent tools for genetic diversity estimation and authentication of medicinal plants. Critical reviews in biotechnology, 36(2), 191-203.

18. Kress, W. J., Wurdack, K. J., Zimmer, E. A., Weigt, L. A., \& Janzen, D. H. (2005). Use of DNA barcodes to identify flowering plants. Proceedings of the National Academy of Sciences, 102(23), 8369-8374.

19. Bafeel, S. O., Arif, I. A., Bakir, M. A., Al Homaidan, A. A., Al Farhan, A. H., \& Khan, H. A. (2012). DNA barcoding of arid wild plants using rbcL gene sequences. Genet Mol Res, 11(3), 19341941.

20. Ved, D.K., Goraya, G.S. (2007). Demand and Supply Position of Medicinal Plants. NMPB, New Delhi FRLHT, Bangalore, India.

21. Mishra, D., \& Patnaik, S. (2020). GC-MS Analysed Phyto-Chemicals and Antibacterial Activity of Withania Somnifera (L.) Dunal Extract in the Context of Treatment to Liver Cirrhosis. Biomedical and Pharmacology Journal, 13(1), 71-78.

22. Khanchandani, N., Shah, P., Kalwani, T., Ardeshna, A., \& Dharajiya, D. (2019). Antibacterial and Antifungal Activity of Ashwagandha (Withania somnifera L.): A review. Journal of Drug Delivery and Therapeutics, 9(5-s), 154-161.

23. Alam, N., Hossain, M., Mottalib, M. A., Sulaiman, S. A., Gan, S. H., \& Khalil, M. I. (2012). Methanolic extracts of Withania somnifera leaves, fruits and roots possess antioxidant properties and antibacterial activities. BMC complementary and alternative medicine, 12(1), 175.

24. Shala, A., Khurana, S.M., \& Kumar, N. (2020). Phytochemistry, antimicrobial and antioxidant activity of Indian ginseng (Withania somnifera (L.)), 8; 137-148.

25. Pfluger, P. T., \& Tschöp, M. H. (2016). Obesity: will withaferin win the war? Nature medicine, 22(9), 970-971.

26. Patel, K., Singh, R. B., \& Patel, D. K. (2013). Pharmacological and analytical aspects of withaferin A: A concise report of current scientific literature. Asian Pacific Journal of Reproduction, 2(3), 238-243.

27. Fathaunnisha, S., Hemamalini, V., Jayasudha, H., Sridhar, R. (2020). A Study on Phytochemical Screening and Analysis of Leaf Extract of Withania Somnifera. International Journal of Scientific Research in Biological Sciences, 7(4), 30-34.

28. Gupta, A., \& Singh, S. (2014). Evaluation of antiinflammatory effect of Withania somnifera root on collagen-induced arthritis in rats. Pharmaceutical biology, 52(3), 308-320.

29. Konar, A., Gupta, R., Shukla, R. K., Maloney, B., Khanna, V. K., Wadhwa, R., ... \& Thakur, M. K. (2019). M1 muscarinic receptor is a key target of neuroprotection, neuroregeneration and memory recovery by i-Extract from Withania somnifera. Scientific reports, 9(1), 1-15.

30. Choudhary, N., \& Singh, V. (2019). Insights about multi-targeting and synergistic neuromodulators in Ayurvedic herbs against epilepsy: integrated computational studies on drug-target and proteinprotein interaction networks. Scientific reports, 9(1), 1-23.

31. Bhatnagar, M., Sharma, D., \& Salvi, M. (2009). Neuroprotective effects of Withania somnifera dunal.: a possible mechanism. Neurochemical Research, 34(11), 1975-1983.

32. Soman, S., Anju, T. R., Jayanarayanan, S., Antony, S., \& Paulose, C. S. (2013). Impaired motor learning attributed to altered AMPA receptor function in the cerebellum of rats with temporal lobe epilepsy: ameliorating effects of Withania somnifera and withanolide A. Epilepsy \& Behavior, 27(3), 484-491.

33. Bhattacharya, S. K., \& Muruganandam, A. V. (2003). Adaptogenic activity of Withania somnifera: an experimental study using a rat model of chronic stress. Pharmacology Biochemistry and Behavior, 75(3), 547-555.

34. Mansour, H. H., \& Hafez, H. F. (2012). Protective effect of Withania somnifera against radiationinduced hepatotoxicity in rats. Ecotoxicology and environmental safety, 80, 14-19.

35. Anwer, T., Sharma, M., Pillai, K. K., \& Iqbal, M. (2008). Effect of Withania somnifera on insulin sensitivity in non- insulin- dependent diabetes mellitus rats. Basic \& clinical pharmacology \& toxicology, 102(6), 498-503.

36. Visavadiya, N. P., \& Narasimhacharya, A. V. R. L. (2007). Hypocholesteremic and antioxidant effects of Withania somnifera (Dunal) in hypercholesteremic rats. Phytomedicine, 14(2-3), 136-142.

37. Aditya, B. S., Priya, J., \& Devi, R. G. (2020). Awareness of Effect of Ashwagandha (Withania somnifera) on Blood Sugar Levels-A Survey. Journal of Pharmaceutical Research International, 96-106.

38. Verma, S. K., \& Kumar, A. (2011). Therapeutic uses of Withania somnifera (ashwagandha) with a note on withanolides and its pharmacological actions. Asian J Pharm Clin Res, 4(1), 1-4.

39. A Dar, P., R Singh, L., A Kamal, M., \& A Dar, T. (2016). Unique medicinal properties of Withania somnifera: Phytochemical constituents and protein component. Current pharmaceutical design, 22(5), 535-540. 
40. Ganie, S. H., Upadhyay, P., Das, S., \& Sharma, M. P. (2015). Authentication of medicinal plants by DNA markers. Plant Gene, 4, 83-99.

41. Ayurvedic Pharmacopoeia Committee. (2001). Ayurvedic Pharmacopoeia of India. Government of India, Ministry of Health and Family Welfare. New Delhi, India: Department of AYUSH.

42. Aboul-Maaty, N. A. F., \& Oraby, H. A. S. (2019). Extraction of high-quality genomic DNA from different plant orders applying a modified CTABbased method. Bulletin of the National Research Centre, 43(1), 25.
43. Pereira, F., Carneiro, J., \& Amorim, A. (2008). Identification of species with DNA-based technology: current progress and challenges. Recent patents on DNA \& gene sequences, 2(3), 187-200.

44. Bolson, M., Smidt, E. D. C., Brotto, M. L., \& Silva-Pereira, V. (2015). ITS and trnH-psbA as efficient DNA barcodes to identify threatened commercial woody angiosperms from southern Brazilian Atlantic rainforests. PloS one, 10(12), e0143049. 